\title{
DETERMINATION OF Zn(II) IN DRINKING WATER USING SEQUENTIAL INJECTION-VALVE MIXING WITH ALIZARIN RED S AS COMPLEXING AGENT
}

\author{
A. Sabarudin ${ }^{1,2 *}$ \\ ${ }^{1}$ Department of Chemistry, Brawijaya University, Malang-65145, Indonesia \\ ${ }^{2}$ Research Center for Advanced System and Material Technology, Brawijaya University, \\ Malang-65145, Indonesia \\ *E-mail : sabarjpn@gmail.com, sabarjpn@ub.ac.id
}

\begin{abstract}
The typical method for determination of $\mathrm{Zn}$ (II) in drinking water is atomic absorption spectrophotometry. However, this method requires a large amount of sample solution, reagent (nitric acid), and also time-consuming. Therefore, in this study, Sequential Injection-Valve Mixing (SI-VM) with RGB Detector at $520 \mathrm{~nm}$ by employing Alizarin Red S (ARS) as the complexing agent was developed for the determination of $\mathrm{Zn}$ (II). The optimum conditions for the complex formation of $\mathrm{Zn}-\mathrm{ARS}$ are as follows: $\mathrm{pH} 4.5$, ARS concentration of $5 \times 10^{-5} \mathrm{M}$, ARS volume of $150 \mu \mathrm{L}$, a sample volume of $50 \mu \mathrm{L}$, the reaction time of $8 \mathrm{~s}$, and flow rate of the reaction products toward detector is $50 \mu \mathrm{L} / \mathrm{s}$. This method is successfully applied to the determination of $\mathrm{Zn}(\mathrm{II})$ in drinking water with a detection limit of 5.9 $\mu \mathrm{g} / \mathrm{L}$ (ppb). High sensitivity, less reagent and sample consumptions $(200 \mu \mathrm{L})$, and high sample throughput (100 sample/h) can be attributed to the advantages of the proposed method.
\end{abstract}

Keywords: Drinking water, Sequential Injection, Alizarin Red S, a Complexing agent, Zinc.

( $\operatorname{RASĀYAN}$. All rights reserved

\section{INTRODUCTION}

Drinking water is water which passes through or not treatment processes, can be drunk and healthy to consume. Drinking water contains various minerals. ${ }^{1}$ One of the most valuable minerals in drinking water is Zinc. ${ }^{2}$ Zinc plays a significant role in the human body. Zinc is used for biological processes, such as gene expression, cellular metabolism, and DNA binding or recognition. ${ }^{3}$ However, excessive $\mathrm{Zn}$ (II) can be toxic to a human. ${ }^{4}$ It can cause Alzheimer's disease and Parkinson's ataxia. Therefore, monitoring zinc is of great importance for biological and environmental purposes.

Determination of Zinc in drinking water commonly uses atomic absorption spectrophotometry ${ }^{5}$, ICPOES, potentiometric methods ${ }^{6}$ and other spectrophotometry methods. However, large amounts of reagents are required for the methods mentioned above, causing environmental damages. To overcome such drawbacks, it is necessary to develop another determination method for $\mathrm{Zn}$ (II) which possesses high accuracy and less reagent consumption. Sequential injection analysis could be considered as the best option of choices.

Sequential injection analysis (SIA) is a system consisting of the syringe pump, holding coil, selection valve and detector. Those are connected with PTFE capillary tubing. ${ }^{7,8}$ SIA is controlled by a computer to minimized human error. ${ }^{9-11}$ Less reagents requirement accompanied by a discrete volume of solution and easy handling could be attributed to this SIA system. ${ }^{12-14}$ However, the formation of the segments in a holding coil resulted in imperfect mixing between reagents and sample. To solve this problem, a mixing chamber/tip can be installed into a selection valve of the SIA system. This developed system can be called sequential injection-valve mixing (SI-VM) as shown in Fig.-1. The SI-VM allows an excellent mixing of reagents with the sample, which results in sensitivity enhancement of an analyte detection. Due to these advantages, the SI-VM system may have great potential to be widely applied in the chemical analysis.

Rasayan J. Chem., 11(4), 1734-1740(2018)

http://dx.doi.org/10.31788/RJC.2018.1144081

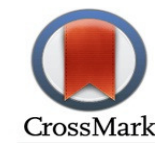


Alizarin Red S (sodium 1,2-dihydroxy-9,10-anthraquinone-sulphonate) is used for bio-labeling ${ }^{15}$, and a complexing agent for trace metal ion. ${ }^{16}$ It can form a specific color with some metal ions. ${ }^{17}$ Therefore, in this work, Alizarin Red S(ARS) was applied as a complexing agent to determine $\mathrm{Zn}$ (II) in drinking water using the SI-VM method. Some factors affecting the sensitivity of the proposed method, which includes physical and chemical parameters, were gently investigated. With a detection limit of $5.9 \mu \mathrm{g} / \mathrm{L}$, total reagent and sample of $200 \mu \mathrm{L}$, and an analysis time of 36s for 1 sample, the proposed SI-VM system provides superiority over other method reported so far.

\section{Chemicals and Instrumentation}

\section{EXPERIMENTAL}

All Chemicals used for this work were of analytical grades. Alizarin Red S (ARS), zinc sulfate heptahydrate, nitric acid, and sodium hydroxide were obtained from Merck. Instrumentation applied for this analysis is the SI-VM composed of a syringe pump (SP; Hamilton, Reno, Nevada, USA) with capacity $2500 \mu \mathrm{L}$, eight-port selection valve (SL; Hamilton, Reno, Nevada, USA), pump, and detector colorimeter RGB-LED at $520 \mathrm{~nm}$. All parts of this system were controlled by a computer using homemade software prepared with a Visual Basic Program.

\section{The Operation Procedures of the SI-VM}

The flow manifold of the SI-VM system used in this work was illustrated in Fig.-1. The operating procedures of the SI-VM system throughout experiment consist of three steps, such as washing, filling PTFE lines, and measurement as the following procedures:

\section{Washing Step}

The syringe valve is set in "in" position, and then the syringe pump is moved to aspirate $2500 \mu \mathrm{L}$ of distilled water with the flow rate of $100 \mu \mathrm{L} / \mathrm{s}$. Then, syringe valve is set in "out" position to dispense water into the holding coil and all PTFE lines which are connected to all ports of selection valve with the flow rate of $50 \mu \mathrm{L} / \mathrm{s}$.

\section{Filling PTFE Lines with a Solution}

Syringe valve is in "out" position. Then, a syringe pump is set to aspirate $500 \mu \mathrm{L}$ of ARS via the port 3 of $\mathrm{SL}$ at a flow rate of $50 \mu \mathrm{L} / \mathrm{s}$. Afterward, a syringe pump is arranged to aspirate $500 \mu \mathrm{L}$ of $\mathrm{Zn}$ (II) sample via the port 4 of SL at a flow rate of $50 \mu \mathrm{L} / \mathrm{s}$. All residual solutions are kept in the holding coil. In the next step, a syringe pump is set to aspirate $1500 \mu \mathrm{L}$ (flow rate: $100 \mu \mathrm{L} / \mathrm{s}$ ) of distilled water, and subsequently, dispense water and the residual solutions to the waste chamber via port 7 of SL. After filling PTFE line with a solution, the SI-VM system is ready for measurement of $\mathrm{Zn}(\mathrm{II})$ in drinking water samples.

\section{Measurement Step}

Syringe valve is in "out" position. Then, a syringe pump is set to aspirate $50 \mu \mathrm{L}$ of $\mathrm{Zn}$ (II) sample via the port 4 at a flow rate of $50 \mu \mathrm{L} / \mathrm{s}$. Afterward, a syringe pump is set to aspirate $150 \mu \mathrm{L}$ of ARS at a flow rate of $50 \mu \mathrm{L} / \mathrm{s}$. Sample and ARS are then dispensed into valve mixing via port 1 (flow rate: $50 \mu \mathrm{L} / \mathrm{s}$ ). The mixture is left to stand for 8s in the VM. After complete reaction, the mixture is sent back to the holding coil. Then, a syringe pump is set to aspirate $1800 \mu \mathrm{L}$ of distilled water at flow rate of $100 \mu \mathrm{L} / \mathrm{s}$. Finally, the mixture of solution (Zn-ARS) as dispensed into the detector for measurement of $\mathrm{Zn}$ (II) concentration at the wavelength of $520 \mathrm{~nm}$. In this step, distilled water is also dispensed via the port 2 of SL at a flow rate of $50 \mu \mathrm{L} / \mathrm{s}$.

\section{RESULTS AND DISCUSSION}

Sensitivity is greatly important for the analysis of $\mathrm{Zn}$ (II) through complexation with ARS. Therefore, some parameters affecting the sensitivity of the proposed SI-VM system which includes chemical parameters ( $\mathrm{pH}$ and concentration of ARS) and physical parameters (volume of ARS, reaction time, and flow rate) were investigated in detail.

\section{Optimization of Chemical Parameters}

Figure-2 showed the effect of $\mathrm{pH}$ on the absorbance of Zn-ARS complex using the SI-VM system. At $\mathrm{pH}$ $\leq 4$, it seems that the Zn-ARS complex could not be formed. From Fig.-2, the highest and stable 1735 
absorbance was achieved when the $\mathrm{pH}$ was adjusted at 4.5 or higher, indicating the Zn-ARS complex occurred at $\mathrm{pH} \geq 4.5$. Probably, at $\mathrm{pH} \geq 4.5$, the phenolic $\mathrm{OH}$ groups of ARS has been deprotonated and it reacted with $\mathrm{Zn}$ (II) to form ARS-Zn(II) complex. Accordingly, $\mathrm{pH} 4.5$ was chosen as optimum $\mathrm{pH}$ and used throughout the experiment.

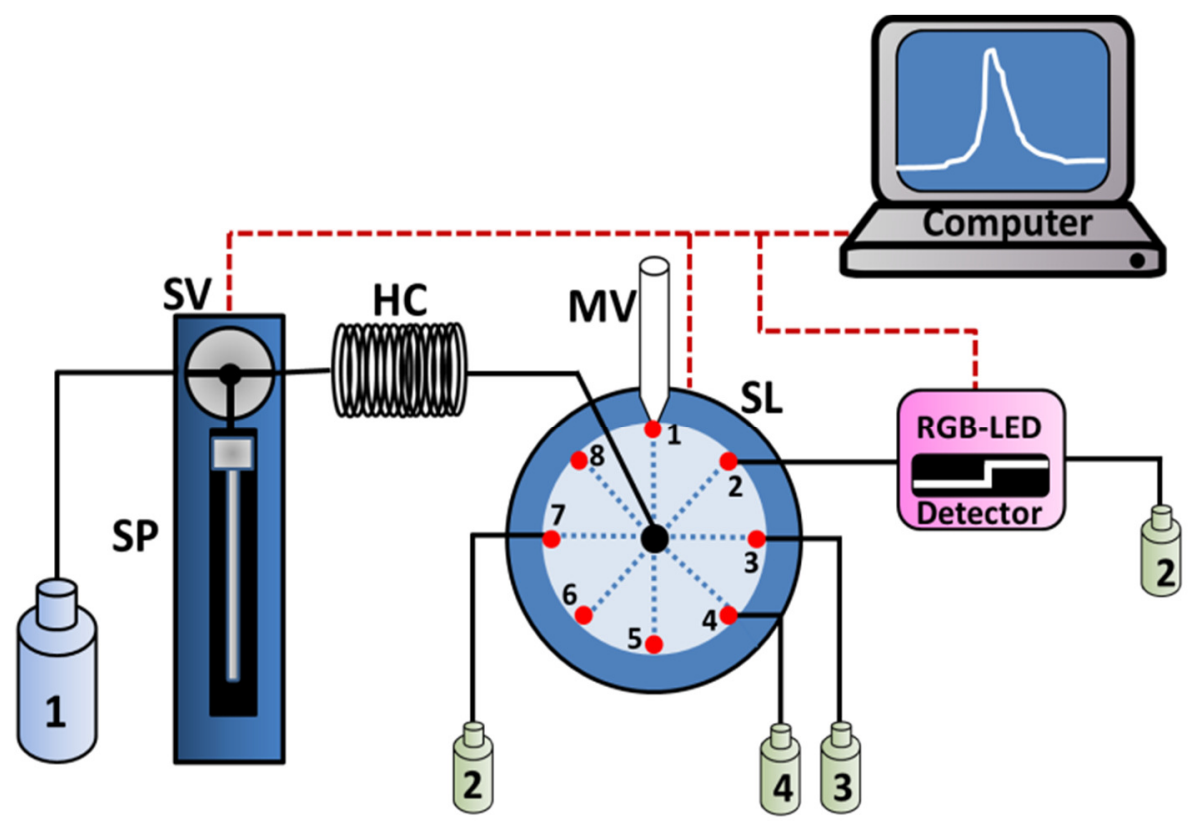

Fig.-1: Manifold of the SI-VM System. SP: Syringe Pump, SV: Syringe Valve, HC: Holding Coil, MV: Mixing Valve, SL: Selection Valve, Distilled Water (1), Waste (2), Alizarin Red S (3), and Sample (4)

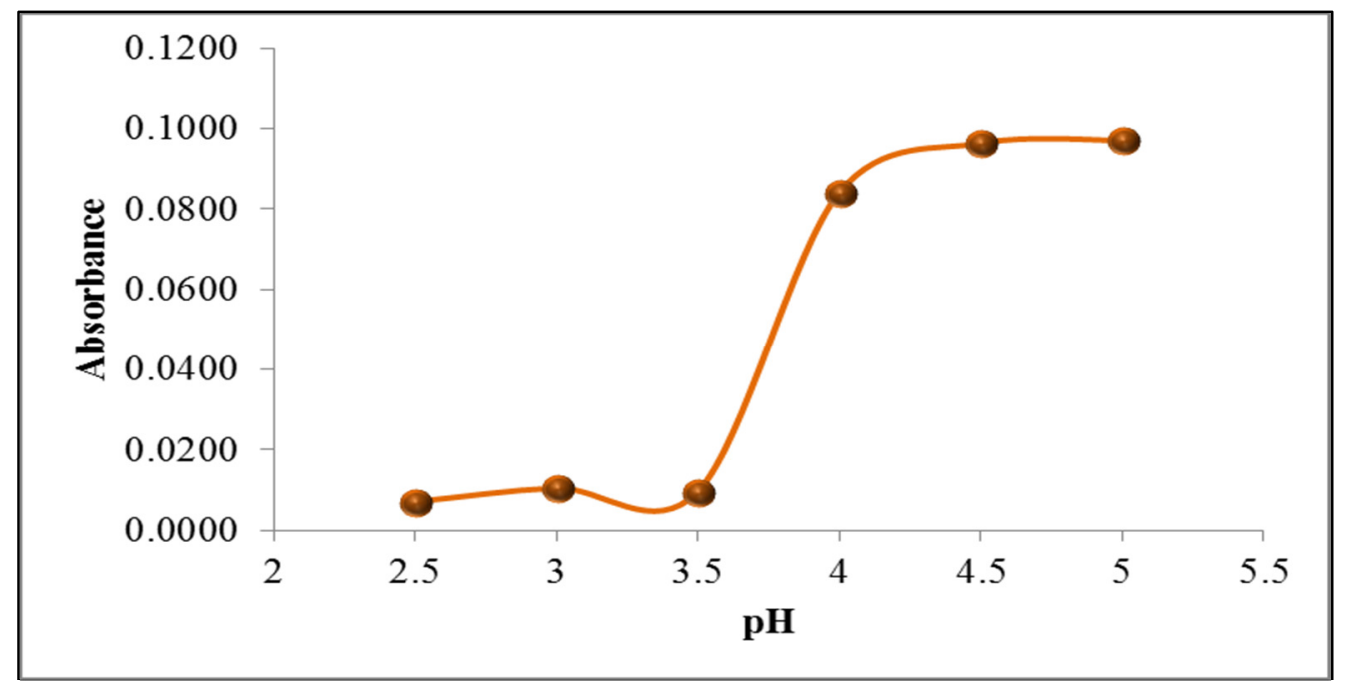

Fig.-2: Effect of pH on the Absorbance of Zn-ARS Complex. Zn(II): 1 ppm, $50 \mu \mathrm{L}$; ARS: ARS $3 \times 10^{-4} \mathrm{M}, 100 \mu \mathrm{L}$, Reaction Time: 13 s; Flow Rate: $50 \mu \mathrm{L} / \mathrm{s}$

Effect of ARS concentration for the formation of Zn-ARS complex by mean of the SI-VM system was investigated as shown in Fig.-3. The absorbance of the complex rose with the increase in ARS concentration. The ARS concentration of $5 \times 10^{-5} \mathrm{M}$ was selected for the further experiment because of largest absorbance differences between blank and sample solution, indicating the highest sensitivity of the proposed method. Additionally, at high concentration of ARS $\left(>5 \times 10^{-5} \mathrm{M}\right)$, the baseline of the resulted peak became increasingly noisy while the reproducibility was unsatisfactory. 


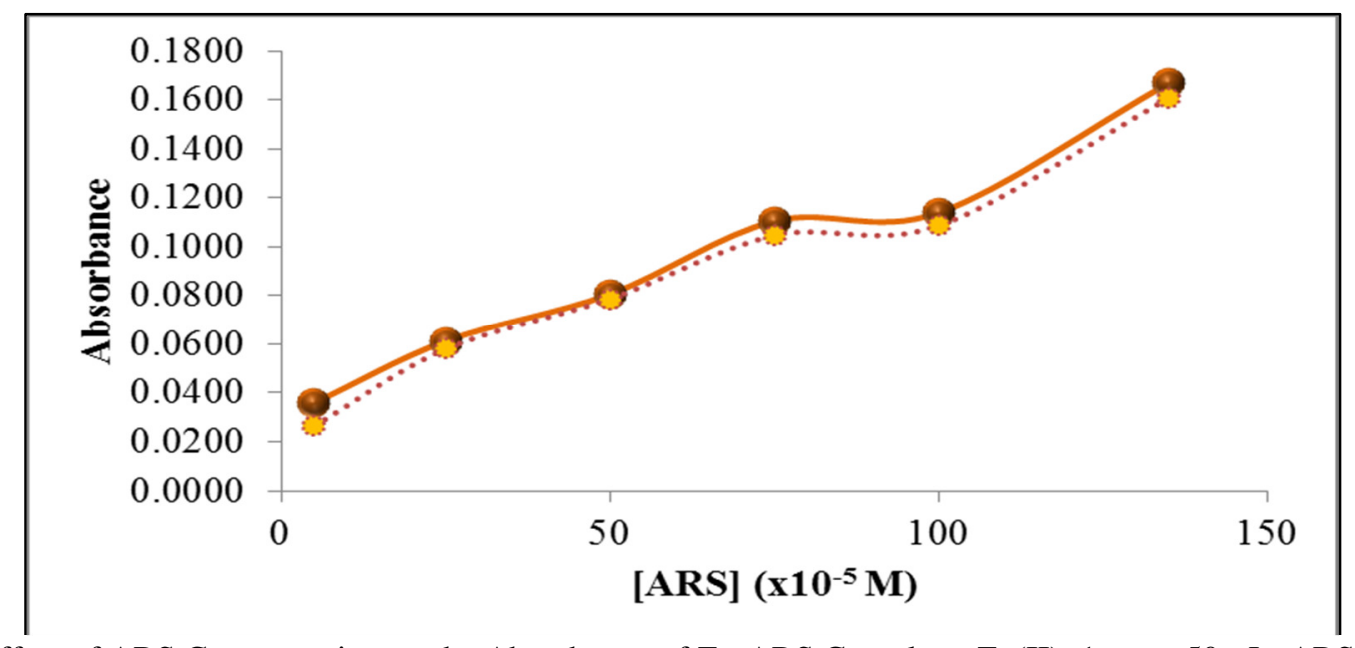

Fig.-3: Effect of ARS Concentration on the Absorbance of Zn-ARS Complex. Zn(II): 1 ppm, $50 \mu \mathrm{L}$; ARS Volume: $100 \mu \mathrm{L}, \mathrm{pH}: 4.5$, Reaction Time: 13 s; Flow Rate: $50 \mu \mathrm{L} / \mathrm{s}$.

Further investigation of the formation of Zn-ARS complex was examined by a batch-wise method to confirm the coordination bond between $\mathrm{Zn}$ and ARS. It was found that the maximum absorbance of the $\mathrm{Zn}$-ARS complex was achieved when the molar ratio of $\mathrm{Zn}$ /ARS is 1:2. This result indicated that 2 moles of ARS reacted with 1 mole $\mathrm{Zn}(\mathrm{II})$ ion to form a five-membered ring of the complex as illustrated in Fig.4.

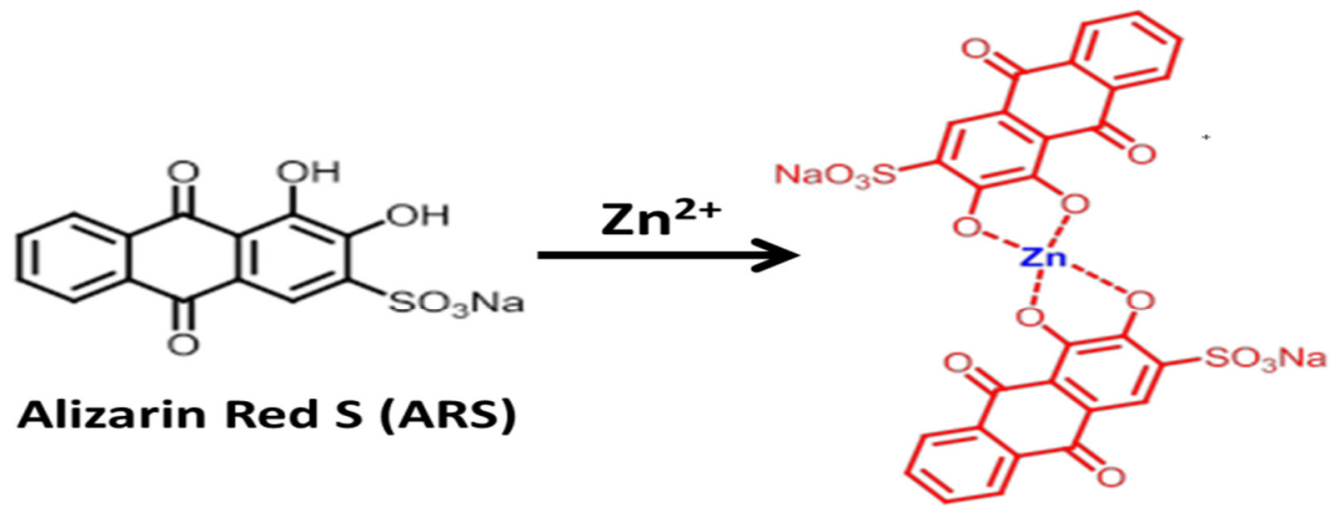

Zn-ARS Complex

Fig.-4: Stoichiometric Coordination of Zn-ARS Complex

\section{Optimization of Physical Parameters}

The effect of ARS volume was examined from 25 to $300 \mu \mathrm{L}$, while the volume of $\mathrm{Zn}$ (II) was kept constant $(50 \mu \mathrm{L})$. For this experiment, concentrations of ARS and $\mathrm{Zn}(\mathrm{II})$ were adjusted to $5 \times 10^{-5} \mathrm{M}$ and $1 \mathrm{ppm}$, respectively. The volume of ARS is useful to estimate the amount of $\mathrm{Zn}$ (II) that can react with ARS. However, attention should be paid because increasing volume of ARS can dilute the sample which may decrease the absorbance of the reaction product (complex). As the results, the peak height (which corresponds to the absorbance) increased as the ARS volume increased from 25 to $100 \mu \mathrm{L}$, and reached nearly constant absorbance from 150 to $300 \mu \mathrm{L}$. As a compromise to the analysis time, $150 \mu \mathrm{L}$ was selected as an optimum ARS volume.

The effect of reaction time on the formation of the Zn-ARS complex was examined from 3 to $25 \mathrm{~s}$ in the mixing chamber of the SI-VM system. As the time is raised, there is a gradual increase in the absorbance, which is showing more extensive the formation of the complex. In this work, the adopted reaction time was 8 s, as a compromise for acceptable reproducibility of the peak and the baseline noise. 
Effect of Zn-ARS complex formed in the VM was investigated from 10 to $70 \mu \mathrm{L} / \mathrm{s}$. Low flow rates increase the possibility of the detector to read the absorbance more accurately, but the high dispersion of Zn-ARS complex into a carrier solution occurred, resulting in a decrease of sensitivity. On the other hand, a high flow rate can cause less accuracy of absorbance measurement although high dispersion can be avoided. Higher peak intensity (absorbance) were obtained in the range of flow rate from 40-60 $\mu \mathrm{L} / \mathrm{s}$. As a compromise of the analysis time and the sensitivity, $50 \mu \mathrm{L} /$ was adopted for further experiment. The conditions optimized for the determination of $\mathrm{Zn}$ (II) using ARS as a complexing agent by employing the SI-VM system were summarized in Table-1.

Table-1: Optimized Parameters for Determination of Zn(II) by The SI-VM

\begin{tabular}{c|c|c|c}
\hline No & Parameter & Examined Range & Optimum condition \\
\hline 1 & $\mathrm{pH}$ & $2.5-5$ & 4.5 \\
\hline 2 & ARS concentration & $(3-140) \times 10^{-5} \mathrm{M}$ & $5 \times 10^{-5} \mathrm{M}$ \\
\hline 3 & ARS volume & $25-300 \mu \mathrm{L}$ & $150 \mu \mathrm{L}$ \\
\hline 4 & Reaction time & $3-25 \mathrm{~s}$ & $8 \mathrm{~s}$ \\
\hline 5 & Flow rate & $10-70 \mu \mathrm{L} / \mathrm{s}$ & $50 \mu \mathrm{L} / \mathrm{s}$ \\
\hline
\end{tabular}

\section{Calibration Curve, Limit of Detection, and Application}

The calibration graph was constructed by varying concentration of $\mathrm{Zn}(\mathrm{II})$ from $0-1 \mathrm{ppm}$ as shown in Fig.-5. Good linearity could be attributed to this graph as the correlation coefficient $\left(R^{2}\right)$ was 0.9967 . The relative standard deviation of 5 measurements of $0.4 \mathrm{ppm} \mathrm{Zn}$ (II) solution was $2.06 \%$, showing the excellent precision of the SI-VM method. High throughput sampling rate (100 samples/h) could be achieved by the proposed method.

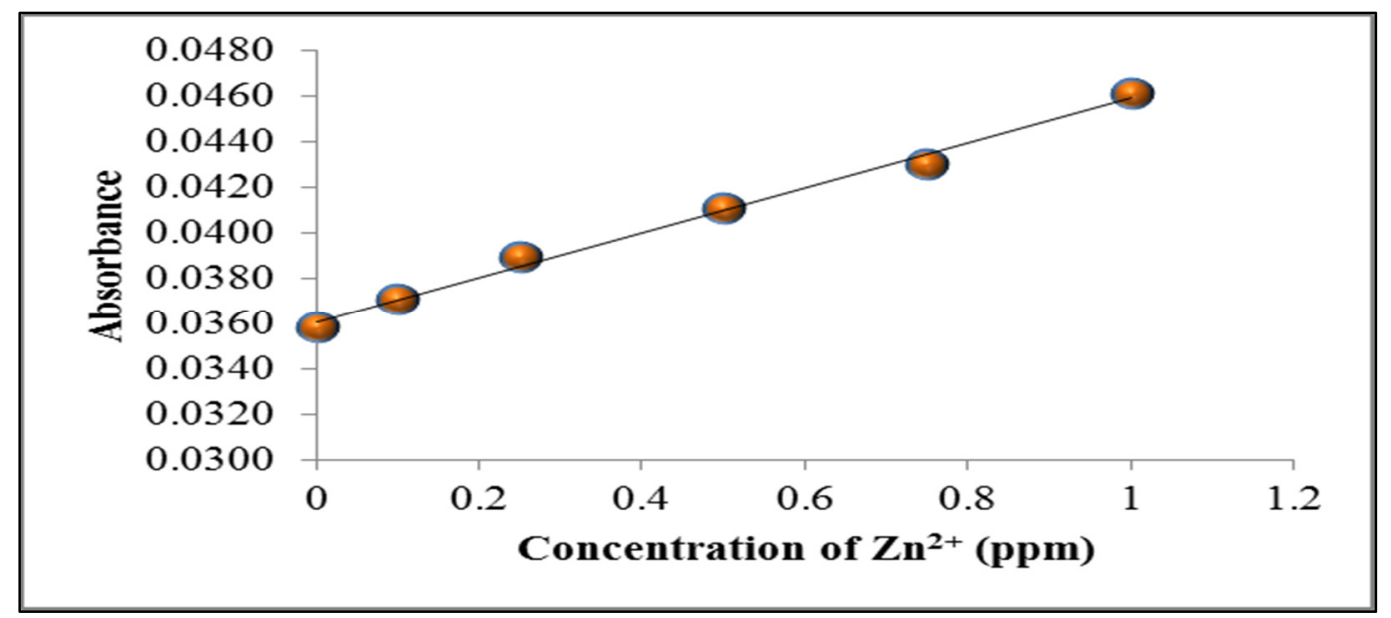

Fig.-5: Calibration Curve for Determination of Zn(II) using the SI-VM Method

The limit of detection (LOD) attained by the SI-VM method was $5.9 \mathrm{ppm}$ of $\mathrm{Zn}$ (II). This LOD was determined by the equation as follows: LOD $=3.3(\sigma / S)$ where $(\sigma)$ is the standard deviation of peak absorbance and $(\mathrm{S})$ is the slope of the calibration curve. The standard deviation is determined according to the standard deviation of the blank solution or Y-intercept of the calibration curve. This calculation method is better than the signal-to-noise ratio $(\mathrm{S} / \mathrm{N})$ method because the bias can be reduced.

The SI-VM method was successfully applied to the determination of $\mathrm{Zn}$ (II) in drinking water samples. In this work, the samples were obtained from 3 refills drinking water companies. The water samples were acidified with nitric acid (3mL concentrated acid for $1 \mathrm{~L}$ sample) and filtered using 0.45 -micron filter paper. ${ }^{18}$ All samples were put in a clean polypropylene bottle and kept in a refrigerator before being aspirated into the SI-VM system. The analytical results of $\mathrm{Zn}$ (II) in drinking water samples were given in Table-2. It was found that results of $\mathrm{Zn}$ (II) concentrations using the SI-VM method were in good 
RASĀYAN J. Chem.

Vol. 11 | No. 4 |1734 - 1740| October - December | 2018

agreement with the atomic absorption spectrophotometry (AAS) method ${ }^{19,20,21}$, showing a good accuracy of the proposed method.

Table-2: Analytical Results of Zn(II) in Drinking Water Samples Determined by the SI-VM and AAS Methods $(\mathrm{n}=5)$

\begin{tabular}{c|c|c|c}
\hline Drinking water & $\mathrm{Zn}(\mathrm{II})$ Concentration $/ \mathrm{ppm}^{* \mathrm{a}}$ & $\mathrm{RSD} / \%$ & $\mathrm{AAS} / \mathrm{ppm}$ \\
\hline $\mathrm{A}$ & $0.330 \pm 0.011$ & 3.33 & $0.342 \pm 0.008$ \\
\hline $\mathrm{B}$ & $0.182 \pm 0.005$ & 2.74 & $0.186 \pm 0.010$ \\
\hline $\mathrm{C}$ & $0.323 \pm 0.007$ & 2.17 & $0.318 \pm 0.008$ \\
\hline
\end{tabular}

${ }^{* a}$ Results obtained by the proposed SI-VM method, ${ }^{* b}$ results obtained by AAS method

\section{CONCLUSION}

The sequential injection analysis coupled with the mixing chamber was successfully developed for the determination of $\mathrm{Zn}$ (II) in drinking water samples using Alizarin Red $\mathrm{S}$ as a complexing agent. High sensitivity, less reagent and sample consumptions, and short analysis time can be attributed as benefits of the proposed method in comparison to the conventional AAS method. Additionally, due to easy-to-use and automatic operation procedures of the SI-VM system, this method has widely potential to be applied to other analysis metal ions in water samples.

\section{ACKNOWLEDGMENT}

This work was supported by Directorate General of Higher Education, Ministry of Education and Culture, Indonesia through Penelitian Unggulan Perguruan Tinggi (PUPT) 2017-2018

\section{REFERENCES}

1. K. Jothivenkatachalam, A. Nithya and S. C. Mohan, Rasayan J. Chem., 3, 649 (2010)

2. J. Wang, Y. Niu, C. Zhang and Y. Chen, Food Chem., 245, 337 (2018), DOI:10.1016/j.foodchem.2017.10.054

3. J.J. Kim, I.H. Hwang, S.P. Jang, J. Kang, S. Kim, I. Noh, Y. Kim, C. Kim and R.G. Harrison, Dalton Trans.,42, 5500 (2013), DOI:10.1039/C3DT33024A

4. H.-Y. Lon, S. Gao and Z. Xi, Inorg.Chem.Commun., 12, 300 (2009), DOI:10.1016/j.inoche.2009.01.013

5. A. Islam, S. Kumar, and H. Ahmad, Food Chem.,213, 775 (2016), DOI: 10.1016/j.foodchem.2016.07.033

6. O.F. Filho, and H.J. Vieira, Eclet. Quim. J.,34, 67 (2009), DOI:10.26850/16784618eqj.v34.2.2009.p67-72

7. N. Kaewwonglom, and J. Jakmunee, Talanta,144, 755 (2015), DOI:10.1016/j.talanta.2015.07.005

8. B.E.R. Cordero, and M.P.Cañizares-Macías, Talanta, 78, 1069 (2009), DOI:10.1016/j.talanta.2009.01.024

9. R. B. R. Mesquita, and A. O. S. S. Rangel, Anal. Chim. Acta,648, 7 (2009), DOI:10.1016/j.aca.2009.06.030

10. D. Costa, M. L. C. Passos, A. M. O. Azevedo, and M. L. M. F. S. Saraiva, Microchem. J.,134, 98 (2017), DOI:10.1016/j.microc.2017.05.010

11. W. Thongchai, B. Liawruangrath, and S. Liawruangrath, Talanta,81, 565 (2010), DOI: $10.1016 /$ j.talanta.2009.12.044

12. N. Ratnawimarnwong, K. Ponhong, N. Teshima, D. Nacapricha, K. Grudpan, T. Sakai, and S. Motomizu, Talanta,96, 50 (2012), DOI:10.1016/j.talanta.2012.02.027

13. P. D. Tzanavaras, Pharm. Anal. Acta, 3, e114 (2012), DOI:10.4172/2153-2435.1000e114

14. A. Sabarudin, N. Lenghor, M. Oshima, L. Hakim, T. Takayanagi, Y.-H. Gao, and S. Motomizu, Talanta, 72, 1609 (2007), DOI:10.1016/j.talanta.2007.01.024

15. M. J. Moester, M. A. Schoeman, I. B. Oudshoorn, M. M. van Beusekom, I. M. Mol, E. L. Kaijzel, C.W. Löwik, and K.E. de Rooij, Biochem. Biophys. Res. Commun,.443, 80 (2014), DOI:10.1016/j.bbrc.2013.11.055 
RASĀYAN J. Chem.

Vol. 11 | No. 4 |1734 - 1740| October - December | 2018

16. P. P. Fehér, M. Purgel, and F. Joó, Comput.Theor. Chem.,1045, 113 (2014), DOI:10.1016/j.comptc.2014.06.025

17. J. Mech, M. A. Grela, and K. Szaciłowski, Dyes Pigm.,103, 202 (2014), DOI:10.1016/j.dyepig.2013.12.009

18. N. R. Bader, Rasayan J. Chem., 4, 49 (2011)

19. S. M. Bombatkar, A. R. Raut, G. H. Murhekar, and V. W.Banewar, Orient. J. Chem.,26, 701 (2010)

20. N.-R. Cha, J.-K. Lee, Y.-R. Lee, H.-J.Jeong, H.-K. Kim, and S.-Y. Lee, Anal. Lett.,43, 259 (2010), DOI: $10.1080 / 00032710903325781$

21. D. Kumar, V. Kumar, and S. Kumari, Rasayan J. Chem., 11, 1477 (2018), DOI: 10.31788/RJC.2018.1143075

[RJC-4081/2018] 